\title{
The Implications of Empathy in Our Contexts ${ }^{1}$
}

\author{
Blanca Ximena Pedraza Hernández \\ xime.her17@hotmail.com.ar
}

Being a teacher entails having to be dynamic and active when facing all of the different challenges that our field demands of us. In this case, English is not an exception to this fact. In order to teach the language, we must undergo a constant reflective process where we make use of our creativity and eclectic view of pedagogy as a means of exploring and understanding our students' particularities. By doing so, we can get to know their backgrounds to foster their learning process.

For that reason, it is fundamental to provide our students with a nurturing environment, especially when we consider that learning English can be traumatic for some students. It is our responsibility to captivate our students and make them feel comfortable. This is what creates a bond between teaching and learning, as well as the important values in throughout the process.

When conducting research for my classes, a relevant aspect kept emerging, which was related to others' emotional awareness. More specifically, I kept finding that students benefitted from an environment that fosters empathy. In this essay, I will discuss this value and its importance in English language teaching and learning.

Empathy is the capacity of worrying and understanding what others feel. According to Lord-Kambitsch (2014), empathy promotes mutual understanding and good relationships among people. Regarding English learning, empathy could contribute significantly to solving problems with language learning. Issues like students' lack of motivation, anxiety, fear of making mistakes, and bullying could be alleviated by an environment that promotes empathy.

\footnotetext{
${ }^{1}$ Reflective essay.
} 


\section{ENRETALUA Dousmoal}

Motivation is one of the main factors that students need when learning any new skill and facing new challenges. Moon (1994) claimed that students have preconceived ideas and attitudes towards English as consequence of their backgrounds. Their social and politic relationships and interactions are not the same. As Nieto (2010) stated, students are situated under particular circumstances and inclined by matters of authority (p. 136). In other words, their conceptions about the world are different, and their attitude towards English reflects this variety. Cultural aspects, thoughts, and ideas about English can be made, modified, and renewed (Nieto, 2010).

According to Brown (2002), motivation entails a reason for learning. Several times, students adopt different attitudes by manifesting changes in their mood due to a lack of motivation. This can affect their learning considerably. In this case, empathy would play an important role in understanding our students' attitudes, needs, likes, and dislikes. Putting ourselves in their shoes makes it easier to act and create the environment students need to learn.

When learning English, I have experienced that students tend to lose their self-confidence and gain anxiety. Brown (2002) said that anxiety was caused by different factors, such as the fear of making mistakes or being made fun of by their peers. Consequently, students with anxiety and low self-confidence are affected in their learning processes. Because of this, it is crucial to understand our students' feelings, as well as help them realize that mistakes are part of everyday learning. People make mistakes and keep making them regardless of their level of English. Building students' self-confidence is key, along with providing spaces of tolerance, support, and respect. In this way, students can have a better disposition in their classes. Above all, they can learn and participate more effectively.

In conclusion, putting ourselves in the others' shoes means listening to our students' feelings and the situations that contribute to mutual understanding. Of course, this also creates 
lasting relationships with our students so they can engage in significant learning.

Being an English teacher has been a gratifying profession for me because it has helped me motivate others so they can reach their goals. At the same time, it is a huge responsibility that requires preparation since our relationship with our students is geared toward their own future. Also, there are a lot of challenges implicit in this process that we must overcome in order to provide our students with knowledge. As I mentioned before, our students come from different contexts, which implies a diversity in their needs. Our objective is to make each class as dynamic as possible without forgetting tat knowledge and empathy must go hand in hand.

\section{References}

Brown, D. (2002). Strategies for success: A practical guide for learning English. San Francisco State University, CA: Longman.

Lord-Kambitsch, E (2014), Introduction to empathy: Activation, definition, construct, think pieces. Journal of the Arts, Humanities, and Social Sciences, 1(1), 1 -8.

Moon, J. (1994). Children learning English: A guidebook for English language teachers. London, UK: Macmillan ELT.

Nieto, S. (2010). Language, culture, and teaching: Critical perspectives ( $2^{\text {nd }}$ ed.). New York, NY: Routledge.

\section{How to cite this essay:}

Pedraza, B. X. (2019). L1 presence in the target language speech. Enletawa Journal, 12(1), 8487.

\section{About the author:}

Blanca Ximena Pedraza Hernández is a Master's in Language Teaching candidate at the Universidad Pedagógica y Tecnológica de Colombia (UPTC). She holds a B.A. in Foreign Languages from the UPTC. Blanca is an English teacher at Colegio la Presentación, Tunja, Colombia 